\title{
Supporting employers to enhance the return to work of cancer survivors: development of a web-based intervention (MiLES intervention)
}

\author{
M. A. Greidanus ${ }^{1}$ (1) • A. G. E. M. de Boer ${ }^{1}$ - C. M. Tiedtke ${ }^{2}$ - M. H. W. Frings-Dresen ${ }^{1}$ - A. E. de Rijk ${ }^{3} \cdot$ S. J. Tamminga ${ }^{1}$
}

Received: 19 July 2019 / Accepted: 1 December 2019 /Published online: 14 January 2020

(C) The Author(s) 2020

\begin{abstract}
Purpose The purpose of this study was to develop an intervention targeting employers, with the aim of enhancing cancer survivors' return to work (RTW).

Methods Intervention Mapping was used to combine information gathered from several procedures involving numerous stakeholders, for example, employers, cancer survivors, oncological occupational physicians, and e-health experts.

Results Employers indicated that they require tailored support during four RTW phases: (1) disclosure, (2) treatment, (3) RTW planning, and (4) actual RTW. The most important employer actions were identified for each RTW phase, for instance, "communicate," "support practically," and "assess work ability," and thereafter formulated as the performance objectives of the intervention. The trans-theoretical model of change was used as a theoretical framework, and several methodologies were employed to induce the desired behavior change, for example modeling, tailoring, and active learning. Subsequently, a webbased intervention with interactive videos, conversation checklists, links to reliable external sources, and succinct, tailored tips and information was developed and adjusted on the basis of pre-tests with different stakeholders.

Conclusions The intervention was developed with input from employers and all relevant stakeholders in the RTW of cancer survivors. The systematic, step-wise development resulted in a succinct and easily accessible intervention targeting the most important employer actions during all RTW phases. As such, the intervention corresponds with employers' needs and preferences in practice.

Implications for cancer survivors By providing employers with support, the intervention could well be the missing link in efforts to optimize the work participation of cancer survivors.
\end{abstract}

Keywords Return to work · Intervention Mapping · Cancer · Internet-Based Intervention · Employer · Cancer Survivors

Electronic supplementary material The online version of this article (https://doi.org/10.1007/s11764-019-00844-z) contains supplementary material, which is available to authorized users.

\section{A. Greidanus}

m.a.greidanus@amsterdamumc.nl

1 Coronel Institute of Occupational Health, Amsterdam Public Health research institute, Amsterdam UMC, University of Amsterdam, Meibergdreef 9, Amsterdam, The Netherlands

2 Department of Public Health and Primary Care, Centre for Environment \& Health, Katholieke Universiteit Leuven, Kapucijnenvoer 35, Leuven, Belgium

3 Department of Social Medicine, Faculty of Health, Medicine and Life Sciences, Research Institute Primary Care and Public Health (CAPHRI), Maastricht University, Duboisdomein 30,

Maastricht, Netherlands

\section{Background}

Since the survival rates of people with a diagnosis of cancer are increasing, appropriate cancer care entails more than just medical treatment [1]. A person's quality of life during and after a treatment for cancer has therefore received more attention in recent decades [1]. An important aspect of the quality of life of cancer survivors is labor participation, as work can provide structure, a sense of normality, and social interaction [2-4].

Physical, psychological, and work-related barriers might prevent cancer survivors from remaining at work during treatment or from returning to work thereafter [5]. Multiple interventions have endeavored to tackle these barriers and thus facilitate the labor participation of cancer survivors $[2,6-8]$. However, these interventions are primarily focused on the cancer survivor him- or herself, and although that appears to 
be an obvious choice, the effects of these interventions on the work participation of cancer survivors have unfortunately not been unambiguous $[2,6,9]$.

From a broader perspective, support from the workplace was found to be a decisive factor in enhancing the labor participation of cancer survivors [10]. The key stakeholder in this broader perspective is the employer, as the employer is in a position to tackle work-related barriers by, for example, allowing a flexible return to work (RTW) plan and providing appropriate practical arrangements for the cancer survivor [11-15]. The role of the employer is therefore essential in facilitating the cancer survivor's RTW.

From an employer's point of view, facilitating a cancer survivor's RTW is not as straightforward as one might think [16-18]. Employers perceive their role in this RTW as complex and demanding [17]. Several dilemmas are experienced by employers, for example, conflicting interests of the cancer survivor and the organization $[17,18]$. Also, an employer's lack of knowledge of cancer and inadequate communication skills, as well as inflexible national and organizational policies, might prevent the employer from giving appropriate RTW support to the cancer survivor $[17,18]$. Several studies therefore recommend providing employers with guidelines and other supportive interventions to enhance the RTW of cancer survivors [2,16-27]. As there was a lack of scientifically sound interventions targeting employers - which might well be the missing link in efforts to optimize the work participation of cancer survivors [16, 21] - we developed one, namely, the MiLES ("the Missing Link: optimizing the return to work of Employees diagnosed with cancer, by Supporting employers") intervention.

A work-related intervention targeting employers is complex, considering, for example, the diversity among cancer survivors, the number of possible employer actions during the RTW trajectory of a cancer survivor, and the required degree of flexibility and tailoring concerning these actions $[18,22,28]$. In order to maximize the probability that an intervention will be effective, it is recommended to develop it systematically [29]. The purpose of the present research was to develop the MiLES intervention, which targets employers during the RTW of cancer survivors and is intended to enhance the cancer survivors' RTW.

\section{Methods}

The Intervention Mapping (IM) approach was used to structure the development of the MiLES intervention [30]. IM is one of the most comprehensive systematic approaches for the development of theory and evidence-based behavior change interventions, and it is a framework that is characterized by a participative approach involving the relevant stakeholders $[29,30]$. This framework has been used regularly in the development and implementation of both cancer-related [31] and work-related interventions [32-35]. The IM framework consists of six consecutive steps, with the results of each step guiding the subsequent one: step 1, needs assessment; step 2, formulating objectives using a logic model of change; step 3 , selecting theories and practical strategies; step 4, developing the intervention; step 5, planning for program adoption and implementation; and step 6, planning for evaluation [30]. Since this paper focuses on the development of the MiLES intervention, only steps 1-4 are presented here. Steps 5 and 6 of the IM framework will be taken in 2019 and 2020.

For each IM step, one or two overarching aims and several sub-aims were formulated (Fig. 1). Various procedures involving numerous relevant stakeholders in the RTW of cancer survivors were used to obtain the desired information or to accomplish these sub-aims. The procedures included interviews, literature reviews, a Delphi study with expert panels, and meetings between the authors and with other relevant experts. More information about some of the procedures can be found in Appendix A.

\section{Results}

\section{Step 1: needs assessment}

\section{Setting}

In the Netherlands, employers have far-reaching legal responsibilities concerning RTW care for employees on sick leave, as laid down in the Dutch Gatekeeper Improvement Act, which requires the active involvement of employers in the work resumption program of employees, right from the start of an employee's absence from work and continuing for a period of 2 years [36]. In addition to this active involvement, Dutch employers are obliged to continue $70 \%$ of the employee's salary payment for 2 years of sick leave if needed, including job protection [36]. All Dutch employees also have, by law, access to an occupational physician, who provides them with health- and labor-related care when they are sicklisted [36]. Occupational physicians also advise employers concerning sickness absence procedures [36].

\section{Needs assessment}

The following concrete needs of employers regarding the RTW of cancer survivors were identified and used as input for subsequent IM steps:

Employers experience complex communication and decision-making during the RTW of cancer survivors [17]. The following RTW phases were identified: 


\section{Overarching aims}

Sub-aims

Procedures

Stakeholders

involved

\section{Step 1: Needs assessment}

To assess the current situation concerning the RTW of cancer survivors, with a specific focus on the role and needs of employers

\begin{tabular}{lll} 
To assess the role and needs of employers & Interviews [16] & Employers (N=30) $)^{1}$ \\
\hline $\begin{array}{l}\text { To identify current RTW interventions } \\
\text { targeting employers }\end{array}$ & $\begin{array}{l}\text { Review of scientific } \\
\text { literature }\end{array}$ & N/A \\
\hline $\begin{array}{l}\text { To identify employer-related perceived } \\
\text { barriers to and facilitators of work } \\
\text { participation }\end{array}$ & $\begin{array}{l}\text { Systematic review of } \\
\text { scientific literature [17] }\end{array}$ & $\begin{array}{l}\text { Employers, cancer } \\
\text { survivors }\end{array}$ \\
\hline $\begin{array}{l}\text { To identify the most important employer } \\
\text { actions }\end{array}$ & Delphi method [21] & $\begin{array}{l}\text { Employers (N=23) } \\
\text { Cancer survivors (N=29) }\end{array}$
\end{tabular}

\section{Step 2: Formulating objectives using a logic model of change}

To formulate specific objectives for To compose a logic model of the problem the intervention
Performed by first author; discussed with all authors, including author with IM experience

To convert the logic model of the problem into a logic model of change
Performed by first author; discussed with all authors, including author with IM experience

\section{Step 3: Selecting theories and practical strategies}

To construct an adequate theoretical basis for the intervention and translate this basis into appropriate methodologies and practical strategies

\begin{tabular}{lll}
$\begin{array}{l}\text { To construct a theoretical basis for the } \\
\text { intervention }\end{array}$ & $\begin{array}{l}\text { Interviews with e-health } \\
\text { experts }(\mathrm{N}=7)^{* 3}\end{array}$ & N/A \\
& $\begin{array}{l}\text { Performed by first author; } \\
\text { discussed with all authors }\end{array}$ & N/A \\
\hline $\begin{array}{ll}\text { To select core values and methodologies for } \\
\text { the intervention }\end{array}$ & $\begin{array}{l}\text { Selected by the first } \\
\text { author; discussed with all } \\
\text { authors; } \\
\text { Based on 1) interviews } \\
{[16] \text { and 2) individual }} \\
\text { interview* }\end{array}$ & $\begin{array}{l}\text { 1) Employers }(\mathrm{N}=30)^{1} \\
\text { cancer support } \\
\text { organization }(\mathrm{N}=1)\end{array}$ \\
\hline $\begin{array}{l}\text { To select practical strategies for the } \\
\text { intervention }\end{array}$ & $\begin{array}{l}\text { Interviews with e-health } \\
\text { experts (N=7)*3 }\end{array}$ & N/A \\
\hline Selected by all authors & N/A
\end{tabular}

Fig. 1 Overview of each IM step: overarching aim(s), sub-aims, procedures, and stakeholders in the RTW of cancer survivors involved in the development of the MiLES intervention. ${ }^{1},{ }^{2}$, and ${ }^{3}$ : the same

1) Disclosure: the period between disclosure of the cancer survivor's illness to the employer and the first treatment

2) Treatment: the period of sick leave during the cancer survivor's treatment

3) RTW planning: the period in which the concrete planning and preparation of the cancer survivor's RTW take place

4) Actual RTW: the period after RTW individuals were involved in these studies, respectively. N/A: not applicable. *: more information about this procedure can be found in Appendix A
Although the Dutch legislation on sick-listed employees is extensive, research revealed that this legislation does not support employers sufficiently in the case of cancer [17]. We therefore hypothesized that employers need to be supported in the active role they have during the RTW of cancer survivors. More specifically, employers need communication skills and 


\section{Step 4: Developing the intervention}

To develop the intervention

\begin{tabular}{lll}
$\begin{array}{l}\text { To assess experiences with developing a } \\
\text { web-based intervention }\end{array}$ & $\begin{array}{l}\text { Interviews with e-health } \\
\text { experts }(\mathrm{N}=7)^{* 3}\end{array}$ & N/A \\
\hline $\begin{array}{l}\text { To develop a 'tone of voice' for the } \\
\text { intervention }\end{array}$ & $\begin{array}{l}\text { Developed by the first } \\
\text { author; discussed with all } \\
\text { authors, including an } \\
\text { expert }\end{array}$ & N/A \\
\hline To develop the content of the intervention & $\begin{array}{l}\text { Developed by the first } \\
\text { author and revised and } \\
\text { discussed by all authors } \\
\text { and finalized by a } \\
\text { professional copywriter } \\
\text { and a graphic designer }\end{array}$ \\
\hline $\begin{array}{l}\text { Scripts and tips developed } \\
\text { by first author and revised } \\
\text { and discussed by all } \\
\text { authors, including a } \\
\text { communication expert }\end{array}$ \\
$\begin{array}{ll}\text { Re develop the videos for the intervention } \\
\text { Recorded and edited by } \\
\text { experienced filmmakers } \\
\text { (N=2), professional actors } \\
\text { (N=2) and the first author; } \\
\text { adjusted based on } \\
\text { feedback from all authors }\end{array}$ \\
\hline N/A \\
\hline
\end{tabular}

To pre-test the intervention

Fig. 1 (continued)
To test whether the content was perceived useful in order to achieve the performance objectives

\section{'Talk-through}

interviews'*

Individual interview*

Individual pre-tests of intervention followed by focus groups $(\mathrm{N}=2)^{*}$
Employers $(\mathrm{N}=4)^{2}$

Oncological occupational physicians $(\mathrm{N}=1)$

Cancer survivors $(\mathrm{N}=8)$ Oncological occupational physicians $(\mathrm{N}=6)$
To test whether the design and userfriendliness was appropriate
'Talk-through interviews'*
Employers $(\mathrm{N}=4)^{2}$ information on how to support cancer survivors during the abovementioned RTW phases [17].

No scientifically sound interventions solely targeting employers to enhance the RTW of cancer survivors were identified [37]. Some patient-oriented RTW interventions involved the employer of a cancer survivor in the intervention by, for example, organizing an RTW meeting with the employer and making a gradual RTW plan in collaboration with the cancer survivor, employer, and occupational physician [38]. However, involving the employer in this type of RTW interventions turned out to be challenging [38]. It is therefore essential to assess the employers' preferences regarding the type and design of the intervention (IM steps 3 and 4), in order to optimize the intervention engagement of employers.

A large variety of employers' behaviors, attitudes, or perceptions were perceived as barriers to or facilitators of the RTW of cancer survivors, such as communication, knowledge about cancer, work environment, and perception of survivors' work ability [18]. These barriers and facilitators were interpreted in terms of the employer's willingness and ability to support a cancer survivor [18], in order to categorize different types of change objectives in IM step 2.

The abovementioned perceived barriers and facilitators were condensed into the most important employer 
actions, according to employers and cancer survivors [22]. The following employer actions were identified by cancer survivors and/or employers as most important for the successful RTW of cancer survivors: "emotional support," "practical support," "allow sufficient sick leave," "plan return to work," "adjust expectations," "assess work ability," "show appreciation," "communicate," "treat normally," and "handle unpredictability." Employers need support to perform these employer actions. The employer actions were all considered to be specific to one to three of the abovementioned RTW phases. It is therefore important that the intervention provides support that is specific to each of the RTW phases. Employers and cancer survivors mostly identified corresponding employer actions, but not during the survivor's sick leave (RTW phase 2). Different perspectives might put effective collaboration between both parties at risk [22]. It is therefore of great importance to have a mutual understanding of each other's needs and preferences throughout the RTW phases [22]. The perspectives held by the cancer survivors also differed considerably [22]. Employers should therefore provide cancer survivors with tailored RTW support.

\section{Step 2: formulating objectives using a logic model of change}

A logic model of the problem was composed and subsequently converted into a logic model of change.

\section{Logic model of the problem}

For each of the most important employer actions (identified in IM step 1), a specific logic model of the problem was composed using the Resource Dependence Institutional Cooperation (RDIC) model of employer support [18], which is based on the RDIC model [39]. The RDIC model of employer support assumes that whether an employer performs a specific employer action properly is determined by the following two concepts:

1) Willingness of the employer, which may be influenced by the employer's perception of the cancer survivor and the employer action

2) Ability of the employer, which may be influenced by the employer's knowledge and skills, as well as by external factors (e.g., regulations or the organization)

The determination and distribution of possible underlying determinants were based on the various studies conducted for the needs assessment (IM step 1). As an example, the logical model for the employer action "emotional support" can be found in Appendix B.

\section{Logic model of change}

The objective of the intervention is to optimize the successful RTW of cancer survivors by supporting the employer. It was hypothesized that adequate support from the employer will optimize the successful RTW of a cancer survivor. In turn, it was assumed that support from the employer will be adequate if the employer is able to perform the most important employer actions throughout the different RTW phases and to tailor these based on the preferences and needs of his or her specific cancer survivor. As an example, the overarching objectives for RTW phase 1 , including the performance objectives concerning the employer actions, and the underlying objectives per employer action related to both the willingness and the ability of the employer, are visualized in Fig. 2.

A specific logic model of change was composed for each employer action separately. While doing so, the logic model of the problem for that specific employer action was kept in mind. Detailed objectives were formulated to indicate the desired behavior. The performance objectives concerning the employer actions during each of the RTW phases, including specific objectives per employer action, all related to both the willingness and the ability of the employer, were the basis of the intervention (see Appendices $\mathrm{C}-\mathrm{F}$ ).

\section{Step 3: selecting theories and practical strategies}

\section{Theoretical basis}

In order to induce the behavior change as formulated in the objectives of the intervention, the trans-theoretical model of change was used as a framework [40]. This model was chosen as it contributed to the understanding of behavior change, and structured the decision on which methodologies and practical strategies to use in order to induce the targeted behavior change. The following stages of behavior were distinguished for the intervention. Stage 1) pre-contemplation, the employer has no intention of executing the employer action; stage 2) contemplation, the employer intends to implement the employer action within a foreseeable time span; stage 3) preparation, the employer intends to implement the employer action directly; and stage 4) action, the employer has made specific adjustments to be able to implement the employer action (Table 1).

\section{Core values and methodologies}

The core values and methodologies of the intervention are (Table 1):

- Practice oriented: employers indicated that the intervention should align with their daily practice, including 


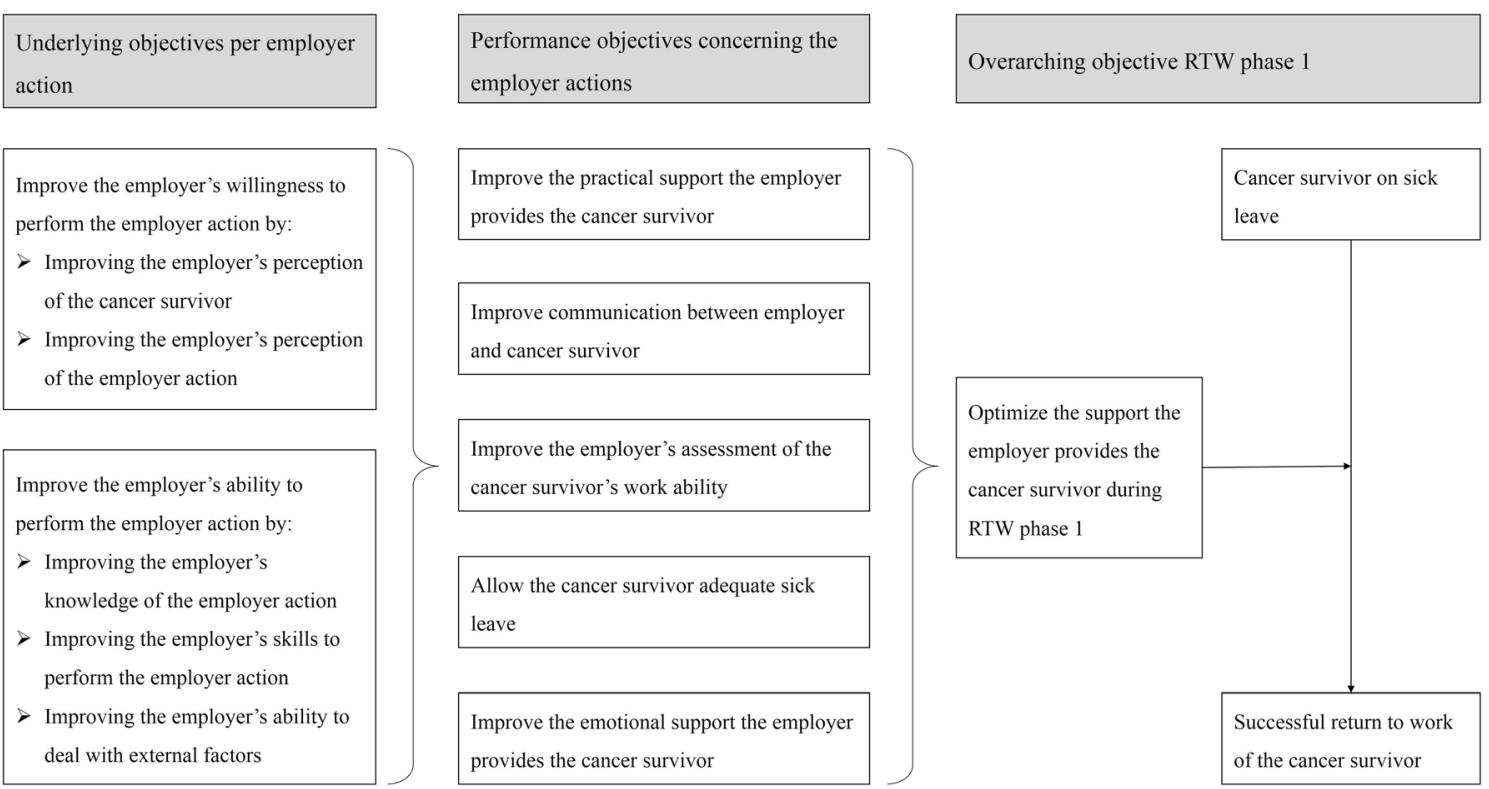

Fig. 2 The various levels of objectives for RTW phase 1: the overarching objective, the performance objectives concerning the employer actions, and, per employer action, the underlying objectives related to the willingness and ability of the employer to perform the employer action. The RDIC model of employer support, which is based on the RDIC model [39], hypothesized that adequate employer support can enhance

realistic and recognizable situations. We therefore included in the intervention communication skills training and modeling as methodologies [30], and offer the intervention at the moment that employers need it.

- Succinct: employers need to be provided with concise and adequate tips and information. Superfluous or repetitive information causes employers to lose interest and thereby leads to lower usage. We therefore chose to tailor the content of the intervention $[30,41]$.

- Stimulating: employers are not always keen to be involved in an RTW intervention for cancer survivors and to provide the required RTW support. We therefore aim to stimulate employers by using a persuasive tone, stating potential positive reinforcement as a result of behavior that the intervention aims to induce, pointing out hypothetical negative consequences if a certain employer action is not performed properly (scenario-based risk evaluation and information about personal risk), involving employers and interacting with them in the intervention (active learning), and letting employers set personal goals (goal setting) [30].

- Trustworthy: employers indicated that they need reliable information and support, in order to avoid unintentionally violating regulations (e.g., privacy regulations).

\section{Practical strategies}

Based on the core values and methodologies of the intervention, it was decided that the MiLES intervention should be a the successful RTW of cancer survivors on sick leave. The employer actions shown in the middle column are perceived as the most important employer actions for the successful RTW of a cancer survivor, according to survivors and employers participating in the Delphi study [22]

web-based intervention comprising interactive videos, conversation checklists, links to reliable external sources, and succinct, tailored tips and information (Table 1). The following strategies were chosen [30]:

- Web-based intervention: an online intervention provides employers with access to the intervention in the way they want it (e.g., via a mobile device, laptop, or tablet) and when they want it (e.g., just before an appointment with a cancer survivor). In order to make the web-based intervention easily accessible and to prevent unintended drop-out, a log-on should not be needed.

- Succinct, tailored tips and information: the content of the intervention should contain concise tips and information that is tailored at several levels: (1) per RTW phase, (2) per employer action, and (3) per "experience type" of cancer survivor [42].

- Interactive videos: communication should be addressed by interactive videos with recognizable conversations between employer and cancer survivor. These videos should visualize how to communicate in different situations and with different "experience types" of cancer survivors [42]. The web-based intervention should also contain an animation video about differences among cancer survivors, to make employers aware that they should tailor their RTW support to the individual needs of the survivor.

- Conversation checklists: the intervention should also contain downloadable conversation checklists that support employers during their conversations with the cancer 
Table 1 Overview of the intended progress concerning the employer's behavior change. The two columns on the right indicate the methodologies and practical strategies used to guide employers through the various stages of behavior change

\begin{tabular}{|c|c|c|c|c|}
\hline $\begin{array}{l}\text { Intended progress behavior } \\
\text { change stages }\end{array}$ & Central question & $\begin{array}{l}\text { Concept model of } \\
\text { employer support }\end{array}$ & Methodologies & Practical strategies \\
\hline $\begin{array}{l}\text { Pre-contemplation } \\
\downarrow \\
\text { Contemplation }\end{array}$ & $\begin{array}{l}\text { Why is this employer action } \\
\text { important? }\end{array}$ & $\begin{array}{l}\text { Willingness of the } \\
\text { employer }\end{array}$ & $\begin{array}{l}\text { Information about } \\
\text { personal risk } \\
\text { O Scenario-based risk } \\
\text { evaluation } \\
\text { O Persuasive } \\
\text { communication } \\
\text { O Tailoring } \\
\text { O Reinforcement }\end{array}$ & $\begin{array}{l}\text { Succinct, tailored tips and } \\
\text { information } \\
\text { o Animation video }\end{array}$ \\
\hline $\begin{array}{l}\text { Contemplation } \\
\downarrow \\
\text { Preparation }\end{array}$ & $\begin{array}{l}\text { How should the employer action be } \\
\text { implemented? }\end{array}$ & Ability of the employer & $\begin{array}{l}\circ \text { Active learning } \\
\circ \text { Communication } \\
\text { skills training } \\
\circ \text { Persuasive } \\
\text { communication } \\
\text { Tailoring } \\
\circ \text { Modeling }\end{array}$ & $\begin{array}{l}\circ \text { Interactive videos } \\
\circ \text { Succinct, tailored tips and } \\
\text { information } \\
\circ \text { Conversation checklists } \\
\circ \text { Links to reliable external } \\
\text { sources }\end{array}$ \\
\hline $\begin{array}{l}\text { Preparation } \\
\downarrow \\
\text { Action }\end{array}$ & What is the next concrete action? & Employer action & $\begin{array}{l}\circ \text { Goal setting } \\
\circ \text { Active learning } \\
\circ \text { Tailoring } \\
\circ \text { Reinforcement } \\
\circ \text { Persuasive } \\
\text { communication }\end{array}$ & $\begin{array}{l}\text { O Conversation checklists } \\
\text { Succinct, tailored tips and } \\
\text { information }\end{array}$ \\
\hline
\end{tabular}

survivor. These checklists should contain relevant topics and illustrative questions and provide space for the employer to take notes during the conversation.

- Links to reliable external sources: the intervention should substantiate its thorough scientific roots, detail the cooperation with a privacy expert, and refer to trustworthy external information sources and additional support services for more comprehensive information and support.

\section{Step 4: developing the intervention}

\section{The intervention: a web-based intervention}

The MiLES intervention is an open-access, web-based intervention. On the homepage is a 1-min animation video about differences between cancer survivors, and a schematic representation of the four RTW phases. Employers are asked to indicate in which RTW phase his or her cancer survivor is currently in.

When the employer clicks on a certain RTW phase, the next webpage consists of content that is tailored to that RTW phase. This content includes an interactive video and the most important tips for that RTW phase. The interactive video starts with a brief scene with an employer and a cancer survivor, followed by interactive video frame footage in which the employer is asked which "experience type" corresponds with his or her survivor. For each of these experience types, a 1-3 min scene is shown, preceded by and concluded with tips on how to communicate with those who experience their diagnosis as such. Below this interactive communication video, the most important tips for that RTW phase are shown in a tab content widget. These tips are limited to five or six concrete, succinct tips that match the performance objectives concerning the employer actions for that RTW phase, as formulated in IM step 2. By clicking on a certain tip, more information is shown about why this tip is important and how to implement it. This information is in certain cases accompanied by an interactive video, a conversation checklist, or a link to external information sources or additional support services. These interactive videos visualize a specific situation including a scene with a good conversation and a scene showing common pitfalls. These scenes are preceded by and concluded with either the most important do's or the most important don'ts for that specific conversation.

In addition to the content per RTW phase, the intervention consists of: 1) a webpage with additional information about how cancer survivors can experience their work situation during and after treatment; 2) a webpage with links to external information sources (e.g., about legislation, privacy regulations, and information about diagnoses and treatments) and additional support services (e.g., oncological occupational physicians and specialized reintegration services); and 3) a webpage with background information about the MiLES project and a substantiation of the thorough scientific roots of the intervention. Lastly, all content can be downloaded as PDF files and printed out. 


\section{Pre-testing}

Four major adjustments have been made to the MiLES intervention as a result of pre-tests with employers, cancer survivors, and oncological occupational physicians. First, the number of conversation checklists has been increased. Second, a webpage has been added where all interactive videos and conversation checklists are collectively displayed. Third, the navigation of the intervention has been simplified, for example, by playing the interactive videos in an embedded light box, instead of in a new tab. Fourth, information about the possible long-term effects of the cancer survivor's sickness and treatment has been added to the webpage of RTW phase 4. Some minor textual changes have also been implemented.

\section{Discussion}

This paper described the development of the MiLES intervention, which targets employers during the RTW of cancer survivors. For this, the systematic IM approach was used to combine information gathered from several procedures involving numerous stakeholders in the RTW of cancer survivors. IM steps 1-4 have been completed, resulting in an open-access, web-based intervention consisting of interactive videos, conversation checklists, and succinct, tailored tips and information. By providing employers with support to fulfill their important though complex role in the RTW of cancer survivors, the MiLES intervention could well be the missing link in efforts to optimize the work participation of cancer survivors [16, 21].

Several tools and interventions for employers, both in the case of cancer and in the case of other chronic diseases, were identified in the gray literature $[37,43]$. In scientific literature, developing and studying RTW interventions targeting employers is still in its infancy, and a broad range of challenges and opportunities have been formulated [16, 26, 44, 45]. In the specific area of the RTW of cancer survivors, the MiLES intervention is the first scientifically substantiated intervention solely targeting employers.

The MiLES intervention differs considerably from RTW interventions that target cancer survivors themselves, predominantly regarding the chosen practical strategies. For cancer survivors, multidisciplinary interventions consisting of, for example, counseling, biofeedback-assisted behavioral training, and an exercise program have been recommended [2]. Also an IM-based RTW intervention for breast cancer survivors consisted of an extensive hospital-based intervention by an occupational therapist, including several counseling sessions [46]. By contrast, the broad range of employers that were involved in the development of the MiLES intervention indicated that they are in need of succinct, easily accessible, online information. IM has been a helpful framework to ensure that the MiLES intervention will meet these specific needs of employers. As such, the MiLES intervention is expected to align their needs and preferences in daily practice, which will assumedly increase the employers' use of and adherence to the intervention, and thereby the chance that the intervention induces the desired behavioral change.

There are also some similarities between the MiLES intervention and other interventions aimed at promoting the RTW of cancer survivors. For example, tailoring is an important aspect not only in the MiLES intervention but also in many other RTW interventions [7, 33, 46-48]. This is an effective technique for behavior change, since it personalizes information, provides less redundant information, and increases the intervention user's attention $[41,47]$. The variability in cancer survivors' perspectives on work [42], their needs and preferences regarding RTW [22], and employers' needs during the RTW of cancer survivors underline the importance of tailoring for the MiLES intervention $[16,17,22,42]$. Most interventions tailor their content on the basis of a baseline questionnaire or an expert opinion [7, 33, 46-48]. The MiLES intervention, however, stimulates employers to tailor the content themselves by, for example, clicking on a certain RTW phase or the cancer survivor's “experience type" in the interactive videos. This active learning challenges employers to actively think about their specific situation and the specific cancer survivor. In line with tailoring, communication also plays an important role in interventions aimed at promoting the RTW of cancer survivors [33, 46, 47, 49]. As effective communication is a prerequisite for a customized RTW plan, stimulating effective employer-cancer survivor communication is one of the main aims of the MiLES intervention.

A major part of the MiLES intervention is believed to be applicable and supportive for employers in other countries. That is because key elements of the MiLES intervention, e.g., communicating with a cancer survivor and tailoring the work-related support to the needs and preferences of the cancer survivor, are mentioned to also be essential actions for employers in other countries [14, 50-54]. Furthermore, a cross-country comparison of employer perspectives on supporting cancer survivors found that experiences and needs of employers are largely comparable [55]. Nevertheless, the RTW phases that structure the intervention might be depending on national legislation and in particular the required employer role. The national social security system in the Netherlands guarantees the continuation of $70 \%$ of an employee's salary payment during 2 years of sick leave, if needed. Therefore, the RTW phase during treatment might often be filled in with (partial) sick leave, and consequently, the next phases have to focus on the planning of, and actual RTW. In countries with less income protection, cancer survivors might try to continue working during treatment and/or take unpaid leave [56]. This might require a less strict division between the guidance during treatment, the planning of, and the actual RTW. However, the content of the intervention will not differ that much, since monitoring is still needed and plans for 
necessary work adaptions have to be made. Also, the intervention is based on the extensive role required from Dutch employers during all phases of RTW, from the moment of disclosure until the RTW. An intervention targeting French employers would, for example, most likely not include the disclosure and treatment phase, since French employers are hardly involved in the guidance of cancer survivors during these phases [57]. We therefore recommend for further research, in each individual country, to study which elements of the MiLES intervention can be retained and which need adaption to the concerning system [27].

Further research on the MiLES intervention is being developed. As such, its perceived utility for employers and its effectiveness for the successful RTW of cancer survivors is being studied. We hypothesize that, because of the systematic development involving numerous stakeholders in the RTW of cancer survivors, the MiLES intervention will meet employers' needs and be feasible in practice.

Acknowledgements The authors would like to thank all participants for their time. We are also thankful to the Dutch online cancer platform kanker.nl for helping us to recruit cancer survivors.

Funding information This work was supported by Dutch Cancer Society grant number UVA 2014-7153.

\section{Compliance with ethical standards}

Conflict of interest The authors declare that they have no conflict of interest.

Ethical approval All procedures performed in studies involving human participants were in accordance with the ethical standards of the institutional and/or national research committee and with the 1964 Helsinki declaration and its later amendments or comparable ethical standards.

Informed consent Informed consent was obtained from all individual participants included in the study, except for the interviewed experts.

Open Access This article is licensed under a Creative Commons Attribution 4.0 International License, which permits use, sharing, adaptation, distribution and reproduction in any medium or format, as long as you give appropriate credit to the original author(s) and the source, provide a link to the Creative Commons licence, and indicate if changes were made. The images or other third party material in this article are included in the article's Creative Commons licence, unless indicated otherwise in a credit line to the material. If material is not included in the article's Creative Commons licence and your intended use is not permitted by statutory regulation or exceeds the permitted use, you will need to obtain permission directly from the copyright holder. To view a copy of this licence, visit http://creativecommons.org/licenses/by/4.0/.

\section{References}

1. McCabe MS, Bhatia S, Oeffinger KC, Reaman GH, Tyne C, Wollins DS, et al. American Society of Clinical Oncology statement: achieving high-quality cancer survivorship care. J Clin Oncol. 2013;31(5):631-40.

2. de Boer AG, Taskila TK, Tamminga SJ, Feuerstein M, FringsDresen MH, Verbeek JH. Interventions to enhance return-to-work for cancer patients. Cochrane Database Syst Rev. 2015;9: CD007569.

3. Stergiou-Kita M, Grigorovich A, Tseung V, Milosevic E, Hebert D, Phan S, et al. Qualitative meta-synthesis of survivors' work experiences and the development of strategies to facilitate return to work. J Cancer Surviv. 2014;8(4):657-70.

4. Wells M, Williams B, Firnigl D, Lang H, Coyle J, Kroll T, et al. Supporting 'work-related goals' rather than 'return to work' after cancer? A systematic review and meta-synthesis of 25 qualitative studies. Psychooncology. 2013;22(6):1208-19.

5. Duijts SF, van Egmond MP, Spelten E, van Muijen P, Anema JR, van der Beek AJ. Physical and psychosocial problems in cancer survivors beyond return to work: a systematic review. Psychooncology. 2014;23(5):481-92.

6. Tamminga SJ, de Boer AG, Verbeek JH, Frings-Dresen MH. Return-to-work interventions integrated into cancer care: a systematic review. Occup Environ Med. 2010;67(9):639-48.

7. Tamminga SJ, van Hezel S, de Boer AG, Frings-Dresen MH. Enhancing the return to work of Cancer survivors: development and feasibility of the nurse-led eHealth intervention Cancer@work. JMIR Res Protoc. 2016;5(2):e118.

8. Zaman AG, Tytgat KM, Klinkenbijl JH, Frings-Dresen MH, de Boer AG. Design of a multicentre randomized controlled trial to evaluate the effectiveness of a tailored clinical support intervention to enhance return to work for gastrointestinal cancer patients. BMC Cancer. 2016;16:303.

9. Lamore K, Dubois T, Rothe U, Leonardi M, Girard I, Manuwald U, et al. Return to Work Interventions for Cancer Survivors: A Systematic Review and a Methodological Critique. Int J Envinron Res Pub Health. 2019;(8):16, 1343.

10. Islam T, Dahlui M, Majid HA, Nahar AM, Mohd Taib NA, Su TT, et al. Factors associated with return to work of breast cancer survivors: a systematic review. BMC Public Health. 2014;14(Suppl 3): S8.

11. Nilsson MI, Petersson LM, Wennman-Larsen A, Olsson M, Vaez M, Alexanderson K. Adjustment and social support at work early after breast cancer surgery and its associations with sickness absence. Psychooncology. 2013;22(12):2755-62.

12. Tamminga SJ, de Boer AG, Verbeek JH, Frings-Dresen MH. Breast cancer survivors' views of factors that influence the return-to-work process - a qualitative study. Scand J Work Environ Health. 2012;38(2):144-+.

13. Tiedtke C, de Rijk A, Dierckx de Casterle B, Christiaens MR, Donceel P. Experiences and concerns about 'returning to work' for women breast cancer survivors: a literature review. Psychooncology. 2010;19(7):677-83.

14. Tiedtke C, Donceel P, Knops L, Desiron H, Dierckx de Casterle B, de Rijk A. Supporting return-to-work in the face of legislation: stakeholders' experiences with return-to-work after breast cancer in Belgium. J Occup Rehabil. 2012;22(2):241-51.

15. Williams-Whitt K, Bultmann U, Amick B 3rd, Munir F, Tveito TH, Anema JR, et al. Workplace interventions to prevent disability from both the scientific and practice perspectives: a comparison of scientific literature, Grey literature and stakeholder observations. J Occup Rehabil. 2016;26(4):417-33.

16. Tamminga SJ, Wolvers MDJ, Greidanus MA, Zaman AGNM, Braspenning AM, Frings-Dresen MHW, et al. Employees diagnosed with Cancer: current perspectives and future directions from an Employer's point of view. J Occup Rehabil 2018.

17. Tiedtke CM, Dierckx de Casterle B, MHW F-D, De Boer A, Greidanus MA, Tamminga SJ, et al. Employers' experience of 
employees with cancer: trajectories of complex communication. J Cancer Surviv. 2017;11:562-77.

18. Greidanus MA, de Boer A, de Rijk AE, Tiedtke CM, Dierckx de Casterle B, MHW F-D, et al. Perceived employer-related barriers and facilitators for work participation of cancer survivors: a systematic review of employers' and survivors' perspectives. Psychooncology. 2018;27(3):725-33.

19. Amir Z, Wynn P, Chan F, Strauser D, Whitaker S, Luker K. Return to work after Cancer in the UK: attitudes and experiences of line managers. J Occup Rehabil. 2010;20(4):435-42.

20. Clur L, Barnard A, Joubert YT. Work adjustment of cancer survivors: an organisational support framework. SA J Ind Psychol. 2017;43:a1468.

21. de Moor JS, Alfano CM, Kent EE, Norton WE, Coughlan D, Roberts $\mathrm{MC}$, et al. Recommendations for research and practice to improve work outcomes among Cancer survivors. J Natl Cancer Inst. 2018;110(10):1041-7.

22. Greidanus MA, Tamminga SJ, de Rijk AE, Frings-Dresen MHW, de Boer AGEM. What employer actions are considered Most important for the return to work of employees with Cancer? A Delphi study among employees and employers. J Occup Rehabil. 2019;29(2):406-22.

23. Petersen KS, Momsen AH, Stapelfeldt CM, Nielsen CV. Reintegrating employees undergoing Cancer treatment into the workplace: a qualitative study of employer and co-worker perspectives. J Occup Rehabil. 2019;29:764-72.

24. Popa R-I. Theoretical perspectives upon the return to work of cancer patients: the difficult path of integration in the organization. Soc Chang Rev. 2015;13(2):113-35.

25. Yarker J, Munir F, Bains M, Kalawsky K, Haslam C. The role of communication and support in return to work following cancerrelated absence. Psychooncology. 2010;19(10):1078-85.

26. Feuerstein $M$. Introduction: engaging employers to prevent disability. J Occup Rehabil. 2016;26(4):393.

27. Bilodeau K, Tremblay D, Durand MJ. Exploration of the contexts surrounding the implementation of an intervention supporting return-to-work after breast cancer in a primary care setting: starting point for an intervention development. J Multidiscip Healthc. 2018;11:75-83.

28. Craig P, Dieppe P, Macintyre S, Michie S, Nazareth I, Petticrew M. Developing and evaluating complex interventions: the new Medical Research Council guidance. Int J Nurs Stud. 2013;50(5):587-92.

29. O'Cathain A, Croot L, Sworn K, Duncan E, Rousseau N, Turner K, et al. Taxonomy of approaches to developing interventions to improve health: a systematic methods overview. Pilot Feasibility Stud. 2019;5:41.

30. Bartholomew LK, Parcel GS, Kok G, Gottlieb NH. Planning health promotion programs; an intervention mapping approach. 2nd ed. San Francisco: Jossey-Bass; 2006.

31. Lamort-Bouche M, Sarnin P, Kok G, Rouat S, Peron J, Letrilliart L, et al. Interventions developed with the intervention mapping protocol in the field of cancer: a systematic review. Psychooncology. 2018;27(4):1138-49.

32. Ammendolia C, Cassidy D, Steensta I, Soklaridis S, Boyle E, Eng $\mathrm{S}$, et al. Designing a workplace return-to-work program for occupational low back pain: an intervention mapping approach. BMC Musculoskelet Disord. 2009;10:65.

33. Munir F, Kalawsky K, Wallis DJ, Donaldson-Feilder E. Using intervention mapping to develop a work-related guidance tool for those affected by cancer. BMC Public Health. 2013;13.

34. Oude Hengel KM, Joling CI, Proper KI, van der Molen HF, Bongers PM. Intervention mapping as a framework for developing an intervention at the worksite for older construction workers. Am J Health Promot. 2011;26(1):e1-10.

35. Fassier JB, Sarnin P, Rouat S, Peron J, Kok G, Letrilliart L, et al. Interventions developed with the intervention mapping protocol in work disability prevention: a systematic review of the literature. J Occup Rehabil. 2019;29(1):11-24.

36. de Rijk A. Work Disability prevention in the Netherlands: A Key Role for Employers. In: MacEachen E, editor. The Science and Politics of Work Disability Prevention. 1st ed. Abingdon: Routledge; 2018.

37. European Agency for Safety and Health at Work. Rehabilitation and return to work after cancer - instruments and practices. Luxembourg: European Union; 2018.

38. Tamminga SJ, Verbeek JHAM, Bos MMEM, Fons G, Kitzen JJEM, Plaisier PW, et al. Effectiveness of a hospital-based work support intervention for female Cancer patients - a multi-Centre randomised controlled trial. PLoS One. 2013;8(5):e63271.

39. de Rijk A, van Raak A, van der Made J. A new theoretical model for cooperation in public health settings: the RDIC model. Qual Health Res. 2007;17(8):1103-16.

40. Prochaska JO, Diclemente CC, Norcross JC. In search of how people change - applications to addictive behaviors. Am Psychol. 1992;47(9):1102-14.

41. Noar SM, Benac CN, Harris MS. Does tailoring matter? Metaanalytic review of tailored print health behavior change interventions. Psychol Bull. 2007;133(4):673-93.

42. Tiedtke C, Dierckx de Casterle B, de Rijk A, Christiaens MR, Donceel P. Breast cancer treatment and work disability: patient perspectives. Breast. 2011;20(6):534-8.

43. Silvaggi F, Leonardi M, Guastafierro E, Quintas R, Toppo C, Foucaud J, et al. Chronic Diseases \& Employment: An Overview of Existing Training Tools for Employers. Int J Environ Res Public Health. 2019;16(5):718.

44. Main CJ, Shaw WS. Hopkinton conference working group on workplace disability P. employer policies and practices to manage and prevent disability: conclusion to the special issue. $\mathrm{J}$ Occup Rehabil. 2016;26(4):490-8.

45. Shaw WS, Main CJ, Pransky G, Nicholas MK, Anema JR, Linton $\mathrm{SJ}$, et al. Employer policies and practices to manage and prevent disability: foreword to the special issue. J Occup Rehabil. 2016;26(4):394-8.

46. Desiron HAM, Crutzen R, Godderis L, Van Hoof E, de Rijk A. Bridging health care and the workplace: formulation of a returnto-work intervention for breast Cancer patients using an intervention mapping approach. J Occup Rehabil. 2016;26(3):350-65.

47. Willems RA, Bolman CA, Mesters I, Kanera IM, Beaulen AA, Lechner L. The Kanker Nazorg Wijzer (Cancer aftercare guide) protocol: the systematic development of a web-based computer tailored intervention providing psychosocial and lifestyle support for cancer survivors. BMC Cancer. 2015;15:580.

48. Zaman A, Tytgat K, van Hezel S, Klinkenbijl JHG, de Boer A, Frings-Dresen MHW. Development of a tailored work-related support intervention for gastrointestinal cancer patients. Eur J Cancer Care (Engl). 2018;27(2):e12782.

49. Brown RF, Owens M, Bradley C. Employee to employer communication skills: balancing cancer treatment and employment. Psychooncology. 2013;22(2):426-33.

50. Stergiou-Kita M, Pritlove C, van Eerd D, Holness LD, Kirsh B, Duncan A, et al. The provision of workplace accommodations following cancer: survivor, provider, and employer perspectives. J Cancer Surviv. 2016;10(3):489-504.

51. McKay G, Knott V, Delfabbro P. Return to work and cancer: the Australian experience. J Occup Rehabil. 2013;23(1):93-105.

52. Isaksson J, Wilms T, Laurell G, Fransson P, Ehrsson YT. Meaning of work and the process of returning after head and neck cancer. Support Care Cancer. 2016;24(1):205-13.

53. Robinson L, Kocum L, Loughlin C, Bryson L, Dimoff JK. I wanted you to know: breast cancer survivors' control of workplace communication about cancer. J Occup Health Psychol. 2015;20(4):446-56. 
54. Dewa CS, Trojanowski L, Tamminga SJ, Ringash J, McQuestion M, Hoch JS. Advice about work-related issues to peers and employers from head and neck Cancer survivors. PLoS One. 2016;11(4):e0152944.

55. de Rijk A, Amir Z, Cohen M, Furlan T, Godderis L, Knezevic B, et al. The challenge of return to work in workers with cancer: employer priorities despite variation in social policies related to work and health. J Cancer Surviv. 2019; https://doi.org/10.1007/s11764019-00829-y.
56. Yin N, Heiland F. Disability policies and public views on work disability: a comparative analysis using anchoring vignette data. Int J Popul Stud. 2017;3(1):42-63.

57. Fassier JB. Work disability prevention in France: organizational and political challenges. In: MacEachen E, editor. The Science and Politics of Work Disability Prevention. 1st ed. Adingdon: Routledge; 2018.

Publisher's note Springer Nature remains neutral with regard to jurisdictional claims in published maps and institutional affiliations. 